\title{
An Analysis of the Neighborhood Impacts of a Mortgage Assistance Program: A Spatial Hedonic Model
}

\author{
Wenhua DI \\ Research Department \\ Working Paper 1001
}

Federal Reserve Bank of Dallas 


\title{
An Analysis of the Neighborhood Impacts of a Mortgage Assistance Program:
}

\section{A Spatial Hedonic Model}

\author{
Wenhua Di \\ Senior Economist, Community Affairs \\ Federal Reserve Bank of Dallas \\ Address: 2200 N. Pearl St., Dallas, TX, 75201 \\ Email:wenhua.di@dal.frb.org \\ Phone: (214) 922-5534 \\ Jielai Ma \\ Research Associate \\ Feinberg School of Medicine, Northwestern University \\ Address: 710 N Lake Shore Drive, Chicago, IL 60611 \\ E-Mail: Jielai-Ma@northwestern.edu \\ Phone: 312-503-2954 \\ James C. Murdoch \\ Professor of Economics and Public Policy \\ University of Texas at Dallas \\ Address: GR31, 800 W. Campbell Rd., Richardson, Texas 75080-3021 \\ E-Mail: murdoch@utdallas.edu \\ Phone: 972-883-4989
}

\section{Acknowledgements}

The City of Dallas and Enterprise Community Partners, Inc. generously provided the database and helpful information on MAP, which made this research possible. The authors would also like to thank Community Affairs staff at the Federal Reserve Bank of Dallas, participants of UT Dallas economics seminars and the sixth biennial Federal Reserve Bank Community Affairs Research Conference, and anonymous reviewers for valuable comments and discussions.

\section{Disclaimer}

The views expressed in the paper are those of the authors and do not necessarily represent the views of the Federal Reserve Bank of Dallas or the Federal Reserve System. 


\title{
An Analysis of the Neighborhood Impacts of a Mortgage Assistance Program: A Spatial Hedonic Model
}

\begin{abstract}
Down payment or closing cost assistance is an effective program in addressing the wealth constraints of low- and moderate-income homebuyers. However, the spillover effect of such programs on the neighborhood is unknown. This paper estimates the impact of the City of Dallas Mortgage Assistance Program (MAP) on nearby home values using a hedonic model of home sales from 1990 to 2006 . We define neighborhoods of 1,000 feet around each sale and estimate the average differences in sales prices between neighborhoods with various numbers of MAP properties before and after their appearance. We find that MAP properties tend to locate in neighborhoods with lower property values; however, unless a concentration of MAP properties forms, the infusion of MAP properties has little detrimental impact on neighboring property values. Moreover, low concentration of MAP properties has a modest positive impact on surrounding property values.
\end{abstract}




\section{INTRODUCTION}

Americans regard owning a home as a fundamental step to asset building. The homeownership rate in the U.S. increased from approximately 48 percent in the 1930 s to nearly 70 percent in 2005 , as a result of the federal government support, legislative efforts, technological and structural changes in the mortgage industry, and favorable economic conditions. The middle class prime market represented the earlier homeownership booms, while lower income and minority borrowers accounted for a substantial share of the most recent boom (Gramlich, 2007).

The push for increased rates of homeownership was largely driven by the belief that homeownership could generate not only individual benefits, such as equity building, better living conditions, and academic performance of children in a stable environment, but also social benefits such as good neighborhood quality, a strong sense of community, and social networks among homeowners (DiPasquale \& Glaeser, 1999; Aaronson, 2000; Harkness \& Newman, 2002; Rohe, Quercia, \& Van Zandt, 2007). However, realizing the benefits of homeownership depends on whether owners can sustain ownership while retaining sufficient resources to support families and communities. The recent recession and the associated fall in home values illustrated that the increased rates of homeownership in the U.S. were not obtained without significant exposure to financial risk. Borrowers with limited income, credit, and financial knowledge were especially attracted by the easy availability of mortgages with low initial payments. When home values fell and interest payments increased, borrowers with limited liquid assets faced the threat of foreclosure, offsetting any gains from homeownership.

A down payment or closing cost assistance program has been one of the most common government-supported approaches to promoting homeownership for low- and moderate-income (LMI) households. Combined with Federal Housing Administration (FHA) or other government- 
backed affordable lending products, these programs effectively overcome the wealth constraints of LMI homebuyers by closing the gap between their limited savings and the down payment requirements for a prime mortgage. Without public assistance, the participants of these public programs might still be renting or have purchased homes with a subprime mortgage. These mortgages are typically underwritten in a traditional way with lenders scrutinizing borrowers' information and have fixed terms with no prepayment penalties. In particular, loan applicants are required to take homeowner education classes and learn about mortgage requirements and homeowner responsibilities. With the assistance, creditworthy borrowers could achieve a lower loan-to-value ratio and build equity faster. There is potentially a lower risk for default because the loan approvals are based on careful assessment of borrowers' repayment ability. There is also potentially a lower risk of prepayment because LMI borrowers are more likely to stay occupied for longer time due to program requirements or limited mobility (Deng \& Gabriel, 2006).

When private mortgage products thrived and housing prices escalated, the market share of mortgages backed by government or originated with the assistance of public programs declined substantially. With the recent meltdown of the subprime market, however, many private options for LMI homebuyers are gone. It is tempting, then, to reconsider traditional programs such as down payment assistance to fill the void.

A small lump sum down payment or closing cost assistance can stimulate a large number of renters to buy homes (Listokin et al., 2001; Quercia, McCarthy, \& Wachter, 2003; Feldman, 2002; Herbert \& Tsen, 2005) - the short-term impact of such programs on individual participants is quite obvious. However, affordable homeownership program should also help build healthy communities. Whether and how such programs generate neighborhood spillovers is unclear. It is possible that these public spending programs have a positive influence on the neighborhood. 
Compared to unsubsidized LMI homeowners who might otherwise occupy the homes, subsidized borrowers pay lower down payments and other housing expenses associated with a fixed and reasonably priced mortgage. They may save extra money to invest in the upkeep of the exterior conditions of their homes and make the neighborhood more attractive. With less financial stress, they may also be more satisfied with the homeownership experience and more involved in community services and school activities. Property values are highly correlated with improved neighborhood conditions and school quality; therefore, homes in proximity may appreciate more than homes without subsidized neighbors. However, unsuccessful homeownership generated by these programs could have a negative influence on participants' neighborhoods (Reid, 2007). The same house would have been occupied by someone with more financial means and would not need the subsidies. Some LMI homebuyers, although subsidized, may still find the mortgage payments, property taxes, home insurance, and maintenance costs overwhelming. When distressed MAP borrowers cannot maintain their homes properly and default on their loans, the neighborhood quality deteriorates and property values in their neighborhood may fall. If the negative spillover effects dominate, these programs may not be a viable option for LMI households and the communities in which they reside.

To date, there has not been much attention given to the existence and direction of the spillover effects of homeownership through public spending programs. Several studies examine the community changes measured by changes in health, social and economic opportunities, and neighborhood property appreciation near dispersed renters with housing vouchers or tax credit properties (Galster, Tatian, \& Smith, 1999; Santiago, Galster, \& Tatian, 2001; Ezzet-Lofstrom \& Murdoch, 2006; Jacob, 2003; Kling, Ludwig, \& Katz, 2007), but only a few attempted to evaluate the impacts of subsidized homeownership programs on individuals or neighborhoods. 
Calem (1993) showed evidence that the Delaware Valley Mortgage Plan was effective in broadening mortgage lender's reach to underserved neighborhoods, and the loan performance was not too bad because of lenders' extensive underwriting process. Smith and Hevener (2005), Schwartz et al. (2006) and Ellen et al. (2007) found that place-based revitalization projects have significant positive spillover effects on the surrounding neighborhood. Di, Ma, and Murdoch (2007) analyzed the experience of Dallas Mortgage Assistance Program (MAP) participants and found no evidence of adverse impact of high concentration of MAP properties on block group median home values. However, their analysis is subject to the possible selection of MAP participants into block groups and the potential endogeneity of block group demographics.

This paper extends the previous literature by integrating data from the City of Dallas MAP with the Multiple Listing Service (MLS) data on single family home sales in Dallas to further explore how subsidized homeownership affects participants' neighborhoods. The basic approach is a hedonic model to estimate the changes in home sale prices before and after the appearance of MAP properties between neighborhoods with and without MAP properties - a difference-in-difference (DID) approach at the individual home level.

Because the main threats to the identification of the MAP impact are unobserved neighborhood attributes, we explicitly model the unobserved similarities among nearby transactions for each sale using techniques from spatial econometrics. This approach is in contrast to incorporating only aggregate covariates based on large neighborhoods such as census tracts or block groups. In addition, we use prices of nearby sales over time for each sale to account for the preexisting trends in the neighborhood housing market. The incorporation of both spatial and temporal correlations among sales addresses the potential selection problems and leads to precise estimates and causal interpretations. 
The findings of this paper contribute to the current policy debate on the validity of public spending programs. If the MAP properties appear to cause a decline in neighboring property values relative to similar neighborhoods without subsidized homeownership, one may question if any individual benefits of homeownership are offset by negative local externalities. Otherwise, we have evidence that may suggest down payment assistance is a reasonable policy instrument to increase LMI homeownership without the increased financial risk that accompanies alternative mortgage products. This paper also contributes to the literature of evaluating spillover effects of public programs by modeling the spatial and temporal patterns in neighborhood changes.

The remainder of the paper is organized as follows. First, we provide an overview of the MAP program by summarizing the characteristics of participants, properties, and loan performance. Then we define "sliding" neighborhoods for each single family sale based on the distance from the location of MAP properties and compare the sales prices of homes with MAP properties close by and those without. We correct for neighborhood housing market trends, unobserved spatial variation, and allow the treatment level (the number of MAP properties) to vary when estimating the impact of MAP infusion on property values. We conclude with policy implications.

\section{OVERVIEW OF THE CITY OF DALLAS MAP}

The City of Dallas MAP was established in October 1991 and has been administered by Enterprise Community Partners, Inc. in Dallas (formerly known as the Enterprise Foundation). As of the end of 2006, Enterprise had closed 5,500 MAP loans with total subsidies exceeding $\$ 50$ million. It is one of the largest down payment assistance programs in the nation, primarily because Dallas has a large supply of housing within the price limits of the FHA 203B 
regulations - the maximum loan amount allowed for such programs. ${ }^{1}$ The Dallas program is funded for the most part with U.S. Department of Housing and Urban Development (HUD) block grants through three programs: HOME Investment Partnerships Program, Community Development Block Grant Program and American Dream Downpayment Initiative.

In the program, the first lien is still a mortgage loan from a traditional lender, while the MAP loan assumes second-lien status. The current second-lien MAP loan has an 8-year recapture period - one eighth of the loan is forgiven each year as long as no default occurs and the property remains the borrower's principal residence. MAP funds are used primarily for down payment and closing cost assistance, although they may also cover some of the seller's repair costs. $^{2}$

There are numerous requirements for both the borrowers and the properties. ${ }^{3}$ In particular, client households must be first-time homebuyers with total household income of less than 80 percent of the Dallas-area median. They must successfully complete a homeowner education course from an approved provider and apply for MAP funding through a city-approved lender. In addition, the property must pass Housing Quality Standards ${ }^{4}$ set by HUD and the city. We obtained the MAP database from Enterprise Community Partners, Inc. in Dallas. Approximately 85 percent of the geocoded MAP properties were located in HUD LMI census tracts. Table 1 presents summary information on the MAP properties from the Enterprise database as of the end of 2006. Before 1997, borrowers' characteristics and loan features were not recorded in the database. On average, MAP participants received a total subsidy of $\$ 11,015$, which included assistance for closing or repair costs and the second-lien (down payment assistance) amount of almost $\$ 9,800$. The appraised values of MAP properties ranged from $\$ 26,000$ to $\$ 168,000$, with an average of $\$ 84,273$ and a median of $\$ 83,000$. The sales prices 
ranged from $\$ 17,500$ to $\$ 159,900$, with an average of $\$ 81,931$; this is lower than the average appraised value, as MAP requires appraisal to be at or above sales price. The average mortgage size was $\$ 73,734$, and a typical MAP property was a three-bedroom single family house for a household of three to four.

[Insert Table 1 here]

All program participants were LMI households. From 1997 to 2006, 1,918 (46.9 percent) fell into an income range below 50 percent of area median income, 1,480 (36.2 percent) fell between 50 percent and 67 percent, and only 693 (17 percent) fell between 68 percent and 80 percent. In terms of race and ethnicity, 2,413 (59 percent) were Hispanic, 1,534 (37.5 percent) were African American, and 128 (3 percent) were white. Approximately 29 percent of the households were headed by females, 30 percent by single parents, and 16 percent by single mothers.

Among the loans made from 1997 to 2006, 74.5 percent were FHA loans and 24.5 percent were conventional loans. Approximately 94 percent of the loans were 30-year, fixedterm loans. The mortgage interest rate on MAP properties ranged from 4.63 percent to 11.99 percent, with mean and median both around 7 percent. The front-end ratio of MAP loans, or the ratio derived by dividing housing expenses by monthly gross income, was available in the database for 3,553 MAP participants with an average of 30 percent. Only seven (or 0.2 percent of) MAP participants have a severe housing cost burden, spending 50 percent or more of income on housing. While the city's percentage of LMI households with severe housing cost burdens in 
2000 was 23.1 percent, for those listed in the database, the average back-end ratio, or the ratio derived by dividing total monthly debt by monthly gross income, was 36 percent.

Di, Ma, and Murdoch (2007) found that the mortgage default rate and foreclosure rate of MAP were lower than that of subprime loans in Texas - the likely alternative for LMI households. MAP loans also outperformed FHA loans in Texas. They concluded that the overall impact on the individual participating households was beneficial because it facilitated homeownership in LMI households with the accompanying gain in wealth without the financial risk that can come with homeownership. MAP households were not likely to purchase a house that was too expensive in relation to their income.

\section{IMPACTS OF MAP ON NEIGHBORHOODS}

The benefits and costs of a program like Dallas MAP can extend beyond the individual participants into surrounding neighborhoods. MAP borrowers may provide positive external benefits to neighboring properties if they can successfully sustain homeownership by preserving their home equity through keeping up the maintenance of their homes and improving neighborhood conditions. However, MAP makes homeownership accessible to an income group that, without the program, would be unlikely to obtain affordable mortgages. Housing expenses may exhaust their financial resources and leave them with no cushion in the event of a financial crisis. To the extent that MAP properties cluster in specific neighborhoods, the program has the potential to produce clusters of poverty—or at least reduced incomes—in neighborhoods that might not otherwise have as many LMI families. The myriad of potential social problems associated with concentrations of poverty and lower levels of income (see, for examples, Brooks- 
Gunn, Duncan, \& Aber, 1997 and Jargowsky, 1997) could cause either a perceived or real change in neighborhood quality and, therefore, generate external costs on neighboring properties.

Community changes are highly correlated with changes in property values, and numerous previous studies use housing sales prices or housing appraisals to measure changes in property values (see, for examples, Ding \& Knaap, 2003; Smith \& Hevener, 2005; Ezzet-Loftstrom \& Murdoch, 2006). We choose home sales prices to measure the neighborhood impact of MAP by comparing the changes in sales prices of homes with MAP properties nearby to sales of homes without MAP neighbors, before and after the infusion of MAP — a DID approach at the individual home level.

\section{Benchmark Hedonic Model}

An appropriate neighborhood definition is critical to studying the impacts on "neighbors." Previous studies, such as Di, Ma, and Murdoch (2007) defined neighborhoods using the U.S. census block groups to examine the impact of MAP. Despite the convenient access to block group-level demographic information, the census boundaries tend to define areas that are too large. For example, in our data, the average block group contains over 100 sales. Other fixed geographies, such as school attendance zones, are even larger. To make a more realistic definition of neighborhood, we implement the "sliding" neighborhood approach (Dubin, 1992) by drawing circles with radii of 1,000 feet around each home sale in the dataset. ${ }^{5}$ These circles define the neighborhood boundaries for each observation. When moving from observation to observation, the neighborhood changes, or slides. This is a more accurate way to define a neighborhood that is close to each property. 
We formulate the treatment and comparison groups of neighborhoods based on the distance to MAP properties. Consider a home sold in 2000. We define two areas around MAP properties — within 1,000 feet and beyond 1,000 feet. The observation must fall within one of three categories: comparison group, treatment group (before treatment), or treatment group (post treatment). If there were no MAP properties within 1,000 feet of the sale at anytime during the study period, the observation is in the comparison group. If there were no MAP properties within 1,000 feet at the time of the sale but one or more MAP within 1,000 feet sometime after the sale (say, a MAP home closed in 2002), the observation is in the treatment group, before treatment. The sale falls in the post-treatment treatment group if there were one or more MAP properties within 1,000 feet at the time of the sale. If MAP matters, we expect to find that MAP properties within 1,000 feet have a greater impact on the sales price than MAP properties beyond 1,000 feet as of the time of the sale. Setting up the treatment and comparison groups with the sliding neighborhoods based on distance rather than census tracts or block group boundaries helps identify influences of neighboring properties more precisely and reduce the unobserved confounding effects in a large area.

For most social programs, the treatment or intervention is not randomly assigned. Neighborhoods with no MAP participants may be affluent areas without housing stock within the price range of MAP, or at the other extreme, so depressed that they are unattractive to potential MAP participants due to a lack of housing that passes the housing quality standards required by the program. We control for the differences between the treatment and comparison groups by using a hedonic model with numerous covariates.

We begin with an Ordinary Least Squared (OLS) regression model to estimate the impact of MAP: 


$$
\log \left(\text { Price }_{i}\right)=\alpha_{0}+\beta X_{i}+\xi Z_{i}+\gamma T_{i}+\alpha_{1} M A P_{i}+\alpha_{2} \text { POSTMAP }_{i}+\varepsilon_{\mathrm{i}}
$$

In model (1), the dependent variable is the natural logarithm of the sales price. $X_{i}$ is a vector of characteristics that are traditionally considered to influence the sales price, such as living area, number of bathrooms, and condition of the house, while $Z_{i}$ is a vector of census block group- and school district-level variables that help further control for variation in the treatment and comparison groups. $T_{i}$ is a vector of variables that control for price trends in the Dallas housing market (described below). $M A P_{i}$ is a dummy variable indicating whether the house is ever within a MAP neighborhood (that is, within 1,000 feet of MAP properties at the time of sale or in the future) or in the treatment group. POSTMAP $i$ is a dummy variable indicating whether the house is within a MAP neighborhood at the time of the sale or in the treatment group, post treatment. Controlling for general and local housing market trends, $\alpha_{2}$ measures the difference-in-differences (DID); a positive estimate of $\alpha_{2}$ means that the existence of MAP properties in a neighborhood has a positive influence on the sales prices in that neighborhood. $\varepsilon_{i}$ is the error term.

We use the MLS data on 95,148 single family home sales within the city of Dallas from 1993 to 2006 to estimate model (1). The data are geo-referenced and include measurements on a wide array of characteristics. The hedonic model estimates the impact of the location and timing of the sales of MAP properties on non-MAP home sales only. Sales prices of MAP home sales are excluded from the study.

In equation (1), $T_{i}$ includes not only quarterly and annual dummy variables to control for the general housing market trends, but also three lagged spatial average prices to capture the neighborhood price trends. To see how these are calculated, again consider a home (denoted by i) sold in 2000. We find the four nearest sales in 1999 (denoted by $j$, where $j=1,2,3,4$ ) and then 
calculate the spatially weighted average of the log of sales prices. The weights are based on distance so that sales within 1,000 feet get greater weights than those beyond 1,000 feet. In particular, we first define $\omega_{i j}=1$ if the $j^{\text {th }}$ nearest sale in 1999 is within 1000 feet of $i$ and $\omega_{i j}=0.25$ if it is beyond 1,000 feet. Next, we define $\omega_{i j}^{S}=\omega_{i j} / \sum_{j=1}^{4} \omega_{i j}$ so that $\sum_{j=1}^{4} \omega_{i j}^{S}=1$.

Then, we compute the one period lagged spatial average as $L P \_L A G 1=\sum_{j=1}^{4} \omega_{i j}^{S} \log \left(\right.$ Price $\left._{j}\right)$. This procedure is repeated for the four sales from 1998 and 1997 (LP_LAG2 and LP_LAG3) that are nearest to the ith sale in 2000. By applying this approach we are able to create localized measures of the historical sales prices for each observation in the data. ${ }^{6}$ These measures vary across neighborhoods and may differ from the overall annual and seasonal changes. Because it is possible that MAP participants systematically identify homes in neighborhoods with relatively promising trends, by including the lagged spatial average of historical prices, we control for these trends and, therefore, avoid attributing any preexisting local trend to the impact of the MAP program.

Table 2 displays descriptions and summary statistics of the 95,148 property sales data. ${ }^{7}$ Even though the sample contains one home that was sold for $\$ 13,500,000$, the average home has a selling price of just $\$ 172,724$, with 1,899 square feet of living area and two bathrooms, is about 39.5 years old and, probably, has central air conditioning and is a single story structure. Sales in each year account for approximately 6 to 9 percent of the sample except 2006 where the data only include sales in the first 2 quarters.

[Insert Table 2 here] 
Of the 95,148 sales, 46.9 percent fall within 1,000 feet of at least one MAP property and 32.7 percent of the sales are homes within 1,000 feet of at least one existing MAP property; that is, they are in the treatment group and after treatment. Moreover, 14.2 percent of the observations are in the treatment group before treatment and 53.1 percent are in the comparison group.

Table 3 presents the results of estimating the benchmark OLS model with robust standard errors. The set of variables in $X$ includes the square footage of living area (in hundreds), age of the home, number of bathrooms, a dummy variable denoting the existence of a pool, number of fireplaces, a dummy variable denoting the existence of central air conditioning, dummy variables denoting the condition of the home (from "fair" to "excellent" with "poor" being the left-out category), and dummy variables for two-story and more than two stories. The estimated coefficients on the structural variables imply, for example, that the marginal value of 100 square feet of living area, a bathroom, a pool, and a fireplace are approximately 2.2 percent, 1.9 percent, 5.6 percent, and 4.5 percent of the sales price, respectively. Older homes and those in better condition also command higher values.

[Insert Table 3 here]

We also include independent school district dummy variables that serve the city of Dallas as well as the percent of the minority population in the block group in 1990. The coefficients on the school district dummies are generally significant and vary substantially. The block group level measure, MINORITY, is negative and significant, implying that neighborhoods with a higher percentage of minority population are associated with lower housing prices. 
As noted above, we control for the housing market trends with annual and quarterly dummy variables and the spatial averages of nearby home sales prices in the previous 3 years. The estimates on the annual dummies show the overall housing appreciation trend in Dallas. Controlling for the number of home sales within 1,000 feet in the year of sale, prices went up 5 to 7 percent in 1994 and 1995 (1993 is the left-out year), slowed substantially in 1996 and 1997, then went up through 2002, followed by decreases in the next couple of years with a return upward in 2005. The variation in sales prices is significantly influenced by prices of nearby sales in previous years. All the coefficients on lagged sale prices based on the average of the 4 nearest sales in the previous years are positive and statistically significant. For example, for every percent increase in the average price of nearby homes sales in the previous year, the home price would have appreciated 0.27 percent, other things equal. Not surprisingly, the influences of the second and third year lags are correspondingly smaller.

The main coefficients of interest are those on the variables MAP and POSTMAP. The estimate of coefficient on MAP is negative and statistically significant, which indicates that all else equal, the homes within 1,000 feet of future MAP properties were sold for approximately 9 percent less than similar homes that were more than 1,000 feet from future MAP even before MAP participants move in. That is, MAP properties tend to appear in areas with relatively low property values. As noted above, this is because MAP participants are limited by income and therefore lower-cost housing options.

The DID estimate of the coefficient on POSTMAP, however, is positive and statistically significant, indicating that houses near existing MAP properties are sold at higher prices than houses without MAP nearby, all else equal. The prices of homes that sell within 1,000 feet of existing MAP properties are approximately 8 percent $(-9$ percent +1 percent) less than similar 
homes that are more than 1,000 feet from MAP. The results from the benchmark model suggest that MAP has positive spillover effects on the neighborhood property values.

\section{Spatial Model}

Housing sales prices are not only affected by the features of the house and historical market trends, but also by the sales prices in the neighborhood at the time of the sale. When negotiating prices, people tend to form judgments about whether a price is too high or too low for the neighborhood by looking at the transactions of their nearest neighbors. Homebuyers may also choose neighbors who are similar to them and make similar decisions on housing. In the benchmark model, even though we control for preexisting neighborhood housing market trends and number of sales in the same year, we do not specify the possible similarities of the proximate sales in the same year. The results could be confounded by the similarities if they are also correlated with MAP. For example, homes can be sold higher or lower simply because of the transactions being handled by certain realtors that are familiar with MAP neighborhoods; or, it is possible that MAP participants choose to live with neighbors of certain characteristics that are likely to affect neighborhood quality in a similar way. If we ignore these potential influences, we might mistakenly attribute them to the impact of MAP.

Convenient approaches to this problem would be to augment model (1) with either census block group dummies or a random effect for each block group. However, including block group fixed effects may mistakenly specify the variation across block groups and mask the variation within block groups as we noted in Table $2 .{ }^{8}$ Estimating model (1) with random effects at the block group level generates similar results, but a post-estimation Hausman-type test indicates a 
rejection of the assumptions that the random effects are uncorrelated with the explanatory variables. Therefore a random effects model is not a good choice either.

To address the concern about unobserved neighborhood attributes, we explicitly model the spatial correlation of sales prices in a neighborhood by allowing the errors at one home sale to be dependent on the errors at neighboring sales. The spatial error model (SEM) is:

$$
\log \left(\text { Price }_{i}\right)=\alpha_{0}+\beta X_{i}+\xi Z_{i}+\gamma T_{i}+\alpha_{1} M A P_{i}+\alpha_{2} \text { POSTMAP }_{i}+\lambda \sum_{1}^{J} w_{i j}^{S} \varepsilon_{\mathrm{ij}}+\phi_{\mathrm{i}}
$$

In model (2), the error term $\varepsilon_{i}$ is the spatially auto-correlated error term and $\lambda$ is the coefficient for the spatial autocorrelation. $\phi_{i}$ is the identically distributed error independent of $\varepsilon_{i j}$. Instead of defining neighbors as those in the same block group that is relatively large and rather arbitrary, we follow the spatial econometrics tradition (Anselin, 1988) to specify neighbors with a spatial weights matrix $(W)$ in much smaller neighborhoods. Each element in $W, w_{i j}^{S}$, gives the strength of the influence between observation $i$ and observation $j$. If the weight is greater than 0 , the two observations are neighbors.

This approach is substantially different than that implied by fixed or random-effects models at the block group level. In both the fixed and random-effects models, all observations within the block group are neighbors with each other and all of the neighbors are given the same weight. While the average number of neighbors in our data using the block group definition is slightly more than 100 , our spatial model allows for only 4 neighbors and those that are farther away get lower weight, so it is much more parsimonious and intuitively realistic given that real estate valuations, all else equal, tend to give the most weight to the nearest transactions.

There are various methods to specify the weights matrix. Like we did above, we again use a nearest-neighbor algorithm to define the neighbors. For each observation, we first find the 
4 nearest neighbors. Then, for the nearest neighbors within 1,000 feet, $w_{i j}=1$, and for the nearest neighbors beyond 1,000 feet, $w_{i j}=0.25$. For all other pairs of observations that are not nearest neighbors, $w_{i j}=0$. The $W$ matrix is 95,148 by 95,148 of $w_{i j}^{S}$ where the "s" superscript denotes that the weights have been standardized by dividing by $\sum_{j=1}^{4} w_{i j}$.

This algorithm has three advantages. First, it reflects the way real estate markets operate. In real transactions, sales prices are largely influenced by "comparable sales" of the nearest neighbors. Second, the algorithm gives the most weight to observations within the neighborhoods that are in the treatment group. Thus, it helps control for unobserved local factors that homebuyers seek. And, third, it produces a sparse weight matrix thereby facilitating manipulation and estimation. ${ }^{9}$

A slight complication in our application is that we have 14 years of data. Observations from different time periods are not allowed to be neighbors of each other. Thus, we apply the nearest-neighbor algorithm year by year, and the final $W$ matrix is block diagonal with the individual years' weights on the diagonal blocks and zeros in the rest of the elements.

The second column in Table 4 shows the estimates of the key variables from Table 3 in the OLS regression model with robust standard errors. The third column displays the results for the key variables after correction for spatial correlation by model (2).${ }^{10}$ The SEM estimates of the coefficients on MAP and POSTMAP have the same signs and similar significance and magnitude as those of the OLS. All else equal, the homes within 1,000 feet of future MAP properties were sold for approximately 12.3 percent less than similar homes that were more than 1,000 feet from future MAP even before MAP participants moved in. The prices of homes that were sold within 1,000 feet of existing MAP properties are approximately 10.9 percent $(-12.2$ percent +1.3 percent) less than similar homes that were more than 1,000 feet from MAP. The estimate of 
LAMBDA is also statistically significant, indicating the presence of spatial autocorrelation and the existence of unobserved neighborhood factors. The estimate of MAP impact is around 1 percent with both the OLS and the SEM. This implies that the spatial model helps address the unobserved neighborhood attributes that lead to the correlation among nearby homes, but the correlation is not necessarily related to MAP infusion.

[Insert Table 4 here]

\section{Variation of Treatment Levels}

So far, we have only tested whether property values are affected by the existence of MAP in the neighborhood by including dummy variables that indicate the proximity and timing of the sales relative to MAP sales. We do not know whether the impact is caused by one MAP property or several. A natural approach to measuring the impact of every additional MAP property infusion is to include number of MAP in the neighborhood and assume that the marginal impact of MAP is constant in a linear specification. However, MAP infusion took place over 14 years of time. Replacing POSTMAP with the total number of existing MAP in the ring would only compare homes sold with various numbers of MAP in the neighborhood with homes sold without any MAP in the neighborhood. There is a lack of comparison of pretreatment groups for deriving marginal impacts of MAP at different levels.

To find out the marginal effects, we divide the sample into mutually exclusive treatment groups and comparison groups for five levels of MAP concentration by constructing additional dummy variables as follows: MAP_1 (equals 1 if there is only 1 MAP property within 1,000 feet), POSTMAP_1 (equals 1 if there is only 1 MAP property and the sale is after the occurrence of the MAP), MAP_2 (equals 1 if there are two MAP properties within 1,000 feet of the sale), 
and POSTMAP_2 (equals 1 if there are just two MAP properties within 1,000 feet and the sale is after the occurrence of the two MAP properties). Similarly, we use MAP_3_4,POSTMAP_3_4, MAP_5_9,POSTMAP_5_9, MAP_10, and POSTMAP_10 to denote treatments of three or four, five to nine, and 10 or more MAP properties. This specification helps identify the incremental effects of MAP on the neighborhoods.

If the neighborhoods ended up having more than one MAP property, the pretreatment sales are grouped into the pretreatment group for the highest level of MAP. This procedure of constructing the pretreatment group avoids using the same sales multiple times for different levels of MAP. The comparisons of sales prices are between homes with existing MAP properties with pretreatment sales in neighborhoods with up to the same number of MAP properties. However, it reduced the numbers of the pretreatment sales at lower levels. As Table 2 shows, 53.1 percent of the sales are in the comparison group and 17.2 percent of the observations are ever within 1,000 feet of just one MAP property $(M A P 1=1)$, while 9.8 percent of the sample is within 1,000 feet of an existing MAP property $(M A P 1=1$ and POSTMAP1=1). The pretreatment groups contain $659,1,011,1,349$, and 786 observations for the treatment of two, three to four, five to nine, and 10 or more MAP properties, respectively. Correspondingly, the post treatment groups contain 4,978, 6,996, 8,177, and 4,316 observations.

The results of the OLS model with robust standard errors and the SEM model for various levels of MAP are reported in the fourth column of Table 4. As in the simple model of treatment presented in Table 3, the pretreatment MAP areas (MAP_1, MAP_2, etc.) still display relatively low conditional mean prices. The coefficients on the MAP dummies range from -0.109 to -0.125 in the SEM model and all of them are significant at conventional levels. Both the OLS and SEM coefficient estimates are positive and significant on POSTMAP_1, and the SEM estimates are 
slightly bigger. For POSTMAP_2, the OLS estimate is not significant but the SEM estimate is marginally significant and positive. The remaining POSTMAP estimates are not significantly different from zero except the SEM estimate on POSTMAP_10, which is negative and significant. These results suggest that scattered MAP properties do no damage to neighborhood property values and may even be beneficial, but as concentrations rise beyond nine within 1,000 feet or a density of approximately 78 per square mile, we have some evidence from the SEM that home values fall.

The main threat to causal inference in our study is the possibility that the appearance of MAP properties is correlated with some unobserved determinant of housing prices. For example, new community development and crime prevention efforts would both raise property values and attract MAP participants. If so, then the coefficient estimates on POSTMAP would include the impact of the unobservable determinant. We discount this possibility for a couple of reasons. First, the inclusion of the lagged spatial averages of selling prices and the number of sales would have picked up anything that makes local housing sales systematically deviate from overall trends and helps identify the influence of MAP. Any new development initiative would move local housing prices in a positive direction relative to the overall trends. But after controlling for the local trends, the influence of the initiative should not confound the MAP impact. We see this in the variable treatment findings. The concentrations of MAP reverse the positive spillover effects of scattered MAP on the neighborhood, which seems unlikely if the results are driven by an unmeasured local initiative. Second, any unobservables that are uncorrelated with the local trends in home sales prices would confound the interpretation only if they systematically coincide with MAP appearance. Considering that approximately 5,000 MAP properties appeared in 485 Census block groups over a 16 year period, such a coincidence is unlikely. Third, 
according to Dallas MAP administrators, the MAP program does not drive the location decisions of participants. Rather, participants work with realtors and lenders to identify properties and then apply for the subsidy. In other words, there does not appear to be a mechanism to cause MAP participants to locate in places that are any different than non-MAP participants. Certainly, without experimental control of the MAP program — such as randomization — we cannot formally

eliminate the possibility of a confounding factor. ${ }^{11}$ However, the spatial and temporal corrections along with anecdotes supported by the program administrators greatly reduce the likelihood of misinterpreting the findings.

\section{DISCUSSION}

Realization of homeownership benefits is neither automatic nor immediate after purchase. As more and more LMI households gain access to homeownership opportunities through a variety of innovative public or private home-financing products, many challenges arise. Borrowers that can barely afford mortgages are not likely to maintain their homes well, which may cause the decline of nearby property values. In recent years, foreclosures associated with the subprime mortgage fallout have been costly for almost all parties, especially neighbors of foreclosed homes. MAP properties do not have unusually high foreclosure rates; hence it is possibly worthwhile to consider augmenting such programs in the wake of the recent financial meltdown. Our analysis suggests that such an expansion may not harm nearby properties unless subsidized properties concentrate at rates greater than nine homes within 1,000 feet away or 78 per square mile. Moreover, when there are only a few MAP properties in the neighborhood, the spillovers effects can be positive. 
Many perceived homeownership benefits are associated with mixed-income neighborhoods, wherein residents experience a safe and diverse environment, better services and amenities, and upward mobility, especially for youth. Unlike the LMI renters in most public housing programs, participants in down payment assistance programs have more flexibility in choosing their home's location and are distributed in a more scattered pattern. With lower housing cost burden, they are more likely to benefit from homeownership even though the majority of MAP participants still reside in LMI census tracts where the affordable units are available. Their successful homeownership would also benefit the neighborhood they choose to locate. Our results show that as long as subsidized properties do not cluster in high density, these homeownership benefits will not be offset by negative spatial externalities. 


\section{REFERENCES}

Aaronson, D. (2000). A note on the benefits of homeownership. Journal of Urban Economics, $47,356-369$.

Anselin, L. (1988). Spatial econometrics: Methods and models. Dordrecht, the Netherlands: Kluwer Academic Publishers.

Brooks-Gunn, J., Duncan, G., \& Aber, J. L. (1997). Neighborhood poverty: Context and consequences for children. (Vol. 1). Policy implications in studying neighborhoods (Vol. 2). New York: Russell Sage Foundation.

Calem, P. S. (1993). The Delaware valley mortgage plan: Extending the reach of mortgage lenders. Journal of Housing Research, 4, 337-358.

Di, W., Ma, J., \& Murdoch, J. C. (2007). The impact of the mortgage assistance program in Dallas, Texas. Williams Review, 2, 59-90.

Deng, Y., \& Gabriel, S. (2006). Risk-based pricing and the enhancement of mortgage credit availability among underserved and higher credit-risk populations. Journal of Money, Credit, and Banking, 38, 1431-1460.

Ding, C., \& Knaap, G. J. (2003). Property values in inner-city neighborhoods: The effects of homeownership, housing investment, and economic development. Housing Policy Debate, 4, 701-727.

DiPasquale, D., \& Glaeser, E. L. (1999). Incentives and social capital: Are homeowners better citizens? Journal of Urban Economics, 45, 354-384.

Dubin, R. (1992). Spatial autocorrelation and neighborhood quality. Regional Science and Urban Economics, 22, 433-452. 
Ellen, I. G., Schwartz, A. E., Voicu, I., \& Schill, M. H. (2007). Does federally subsidized rental housing depress neighborhood property values? Journal of Policy Analysis and Management, 26, 257-280.

Ellen, I. G., \& Voicu, I. (2006). Nonprofit housing and neighborhood spillovers. Journal of Policy Analysis \& Management, 25, 31-52.

Ezzet-Lofstrom, R., \& Murdoch, J. C. (2006). The effect of low-income housing tax credit units on residential property values in Dallas. Williams Review, 1, 107-124.

Feldman, R. J. (2002, April). 2001 annual report essay: Mortgage rates, homeownership rates, and government-sponsored enterprises. The Region. Retrieved June 3, 2010, from http://www.minneapolisfed.org/pubs/region/02-04/2001AR.pdf.

Galster, G., Tatian, P., \& Smith, R. (1999). The impact of neighbors who use section 8 certificates on property values. Housing Policy Debate, 10, 879-917.

Gramlich, E. M. (2007). Subprime mortgages, America's latest boom and bust. Washington, DC: The Urban Institute Press.

Harkness, J., \& Newman, S. (2002). Homeownership for the poor in distressed neighborhoods: Does this make sense? Housing Policy Debate, 13, 597-630.

Herbert, C. E., \& Tsen, W. (2005). The potential of downpayment assistance for increasing homeownership among minority and low-income households. Washington, DC: U.S. Department of Housing and Urban Development, Office of Policy Development and Research.

Hollister, R. G. (2008). The role of random assignment in social policy research. Journal of Policy Analysis and Management, 27, 402-407. 
Jacob, B. A. (2003). Public housing, housing vouchers and student achievement evidence from public housing demolition in Chicago. Working paper W9652. Cambridge, MA: National Bureau of Economic Research.

Jargowsky, P. (1997). Poverty and place: Ghettos, barrios and the American city. New York: Russell Sage Foundation.

Kling, J. R., Ludwig, J., \& Katz, L. F. (2007). Experimental analysis of neighborhood effects. Econometrica, 75, 83-119.

Listokin, D., Wyly E. K., Schmitt, B., \& Voicu, I. (2001). The potential and limitations of mortgage innovation. Housing Policy Debate, 12, 465-513.

Nathan, R. P. (2008). The role of random assignment in social policy research. Journal of Policy Analysis and Management, 27, 410-415.

Quercia, R. G., McCarthy, G. W., \& Wachter, S. M. (2003). The impacts of affordable lending efforts on homeownership rates. Journal of Housing Economics, 12, 29-59.

Reid, C. K. (2007). Locating the American dream: Assessing the neighborhood benefits of homeownership. In W. M. Rohe \& H. L. Watson (Eds.), Chasing the American dream: New perspectives on affordable homeownership. Ithaca, NY: Cornell University Press.

Rohe, W. M., Quercia, R. G., \& Van Zandt, S. (2007). The social-psychological effects of affordable homeownership. In W. M. Rohe, \& H. L. Watson (Eds.), Chasing the American dream: New perspectives on affordable homeownership. Ithaca, NY: Cornell University Press. 
Santiago, A. M., Galster, G. C., \& Tatian, P. (2001). Assessing the property value impacts the dispersed housing subsidy program in Denver. Journal of Policy Analysis and Management, 20, 65-88.

Smith, M. M., \& Hevener, C. C. (2005). The impact of housing rehabilitation on local neighborhoods: the case of St. Joseph's Carpenter Society. Federal Reserve Bank of Philadelphia Community Affairs Discussion Paper 05-02. Retrieved June 3, 2010, from http://www.phil.frb.org/community-development/publications/discussionpapers/discussionpaper-camdenredevelopment.pdf.

Schwartz, A. E., Ellen, I. G., Voicu, I., \& Schill, M. H. (2006). The external effects of placebased subsidized housing. Regional Science and Urban Economics, 36, 679-707. 
Table 1. Summary Statistics of MAP

\begin{tabular}{lccccc}
\hline Variable & $\begin{array}{c}\text { No. of } \\
\text { observations }\end{array}$ & Mean & $\begin{array}{c}\text { Standard } \\
\text { deviation }\end{array}$ & Minimum & Maximum \\
\hline Total subsidy $(\$)^{*}$ & 5,389 & 11,015 & 4,408 & 990 & 38,504 \\
\hline Second lien amount $(\$)^{*}$ & 5,066 & 9,796 & 4,407 & 501 & 38,504 \\
\hline First lien amount (\$) & 4,091 & 73,734 & 21,380 & 12,240 & 158,646 \\
\hline Appraised value (\$) & 4,045 & 84,273 & 20,541 & 26,000 & 168,000 \\
\hline Sales price (\$) & 4,091 & 81,931 & 20,218 & 17,500 & 159,900 \\
\hline Front-end ratio & 3,553 & 0.30 & 0.06 & 0.1 & 1 \\
\hline Back-end ratio & 3,543 & 0.36 & 0.08 & 0.1 & 0.99 \\
\hline Mortgage interest rate (\%) & 3,881 & 7.08 & 0.97 & 4.63 & 11.99 \\
\hline Household size & 4,081 & 3.31 & 1.52 & 1 & 9 \\
\hline Number of bedrooms & 4,042 & 2.97 & 0.50 & 1 & 6 \\
\hline Not & & & & &
\end{tabular}

Note:

Only nonzero amount is summarized because zeros are not separable in the database from missing values. All data are from 1997 to 2006 except the lien amount and subsidy amount, which are from 1991 to 2006. 
Table 2. Variable Definitions and Summary Statistics (95,148 Sales in MLS data)

\begin{tabular}{|c|c|c|c|c|}
\hline Variable & Description & Mean & Minimum & Maximum \\
\hline PRICE & Selling price & 172,724 & 1000 & $13,500,000$ \\
\hline LPRICE & Natural logarithm of PRICE & 11.675 & 6.908 & 16.418 \\
\hline LIVAREA & Square feet of living area & 1,899 & 358 & 32,153 \\
\hline$A G E$ & Age of the house in years & 39.5 & 0 & 103 \\
\hline BATHS & Number of bathrooms & 2.056 & 0 & 10 \\
\hline POOL & Existence of a pool & 0.137 & 0 & 1 \\
\hline FIREPLACE & Number of fireplaces & 0.710 & 0 & 10 \\
\hline CENTRALAIR & Existence of central air conditioning & 0.838 & 0 & 1 \\
\hline FAIR & In fair condition & 0.092 & 0 & 1 \\
\hline GOOD & In good condition & 0.254 & 0 & 1 \\
\hline VERY GOOD & In very good condition & 0.188 & 0 & 1 \\
\hline EXCELLENT & In excellent condition & 0.153 & 0 & 1 \\
\hline STORIES 2 & Two stories & 0.094 & 0 & 1 \\
\hline STORIES3 & Three stories & 0.065 & 0 & 1 \\
\hline$L P \_L A G 1$ & $\begin{array}{l}\text { Spatial average of the natural log of sales prices } \\
\text { in the previous year }\end{array}$ & 11.620 & 7.966 & 14.983 \\
\hline$L P \_L A G 2$ & $\begin{array}{l}\text { Spatial average of the natural log of sales prices } \\
\text { two years ago }\end{array}$ & 11.571 & 7.469 & 14.927 \\
\hline$L P \_L A G 3$ & $\begin{array}{l}\text { Spatial average of the natural log of sales prices } \\
\text { three years ago }\end{array}$ & 11.526 & 7.469 & 14.944 \\
\hline QUARTER1 & Sold in first quarter & 0.233 & 0 & 1 \\
\hline QUARTER2 & Sold in second quarter & 0.287 & 0 & 1 \\
\hline QUARTER3 & Sold in third quarter & 0.254 & 0 & 1 \\
\hline SALES & $\begin{array}{l}\text { Number of homes sold within } 1000 \text { feet of this } \\
\text { home this year }\end{array}$ & 8.516 & 0 & 66 \\
\hline MAP & Home within 1000 feet of any MAP & 0.469 & 0 & 1 \\
\hline POSTMAP & $\begin{array}{l}\text { Home within } 1000 \text { feet of any MAP- } \\
\text { Sold after MAP }\end{array}$ & 0.327 & 0 & 1 \\
\hline MAP_1 & Home within 1000 feet of just 1 MAP & 0.172 & 0 & 1 \\
\hline POSTMAP_1 & $\begin{array}{l}\text { Home within } 1000 \text { feet of just } 1 \text { MAP_-Sold after } \\
\text { MAP }\end{array}$ & 0.098 & 0 & 1 \\
\hline MAP_2 & Home within 1000 feet of just 2 MAP & 0.059 & 0 & 1 \\
\hline POSTMAP_2 & $\begin{array}{l}\text { Home within } 1000 \text { feet of just } 2 \text { MAP_-Sold after } \\
\text { MAP }\end{array}$ & 0.059 & 0 & 1 \\
\hline MAP_3_4 & Home within 1000 feet of just 3 or 4 MAP & 0.084 & 0 & 1 \\
\hline POSTMAP_3_4 & $\begin{array}{l}\text { Home within } 1000 \text { feet of just } 3 \text { or } 4 \text { MAP_-Sold } \\
\text { after MAP }\end{array}$ & 0.080 & 0 & 1 \\
\hline MAP_5_9 & Home within 1000 feet of 5-9 MAP & 0.100 & 0 & 1 \\
\hline POSTMAP_5_9 & $\begin{array}{l}\text { Home within } 1000 \text { feet of 5-9 MAP_-sold after } \\
\text { MAP }\end{array}$ & 0.089 & 0 & 1 \\
\hline MAP_10 & Home within 1000 feet of 10 or more MAP & 0.054 & 0 & 1 \\
\hline POSTMAP_10 & $\begin{array}{l}\text { Home within } 1000 \text { feet of } 10 \text { or more MAP- } \\
\text { Sold after MAP }\end{array}$ & 0.045 & 0 & 1 \\
\hline MINORITY & Proportion of population minority in block group & 0.322 & .004 & 1 \\
\hline
\end{tabular}


Table 3. Benchmark Estimates of MAP Impacts on Neighborhood Property Values

\begin{tabular}{|c|c|c|c|}
\hline \multicolumn{4}{|c|}{ Dependent Variable: Log (Sales Price) } \\
\hline Variable & Estimate & Variable & Estimate \\
\hline \multirow[t]{2}{*}{ LIVAREA } & $0.0216^{* * *}$ & Y1994 & $0.0498 * * *$ \\
\hline & $(0.000529)$ & & $(0.00543)$ \\
\hline \multirow[t]{2}{*}{$A G E$} & $0.00225^{* * *}$ & Y1995 & $0.115 * * *$ \\
\hline & $(7.74 \mathrm{e}-05)$ & & $(0.00556)$ \\
\hline \multirow[t]{2}{*}{ BATHS } & $0.0191 * * *$ & Y1996 & $0.124 * * *$ \\
\hline & $(0.00329)$ & & $(0.00531)$ \\
\hline \multirow[t]{2}{*}{ POOL } & $0.0555 * * *$ & Y1997 & $0.132 * * *$ \\
\hline & $(0.00307)$ & & $(0.00517)$ \\
\hline \multirow[t]{2}{*}{ FIREPLACE } & $0.0448 * * *$ & Y1998 & $0.181 * * *$ \\
\hline & $(0.00249)$ & & $(0.00505)$ \\
\hline \multirow[t]{2}{*}{ CENTRALAIR } & $0.151 * * *$ & Y1999 & $0.225 * * *$ \\
\hline & $(0.00350)$ & & $(0.00522)$ \\
\hline \multirow[t]{2}{*}{ FAIR } & $0.219 * * *$ & $Y 2000$ & $0.281 * * *$ \\
\hline & $(0.00903)$ & & $(0.00526)$ \\
\hline \multirow[t]{2}{*}{ AVERAGE } & $0.353 * * *$ & Y2001 & $0.297 * * *$ \\
\hline & $(0.00841)$ & & $(0.00545)$ \\
\hline \multirow[t]{2}{*}{ GOOD } & $0.422 * * *$ & Y2002 & $0.303 * * *$ \\
\hline & $(0.00837)$ & & $(0.00561)$ \\
\hline \multirow[t]{2}{*}{ VERYGOOD } & $0.494 * * *$ & $Y 2003$ & $0.285 * * *$ \\
\hline & $(0.00840)$ & & $(0.00584)$ \\
\hline \multirow[t]{2}{*}{ EXCELLENT } & $0.572 * * *$ & Y2004 & $0.228 * * *$ \\
\hline & $(0.00860)$ & & $(0.00592)$ \\
\hline \multirow[t]{2}{*}{ STORIES2 } & $0.0122 * * *$ & Y2005 & $0.257 * * *$ \\
\hline & $(0.00374)$ & & $(0.00561)$ \\
\hline \multirow[t]{2}{*}{ STORIES3 } & $0.0900 * * *$ & $Y 2006$ & $0.340 * * *$ \\
\hline & $(0.00525)$ & & $(0.00739)$ \\
\hline \multirow[t]{2}{*}{ MINORITY } & $-0.178 * * *$ & QUARTER1 & $-0.0465 * * *$ \\
\hline & $(0.00540)$ & & $(0.00282)$ \\
\hline \multirow[t]{2}{*}{ ISD2 } & $-0.159 * * *$ & QUARTER2 & $-0.00456^{*}$ \\
\hline & $(0.0138)$ & & $(0.00255)$ \\
\hline \multirow[t]{2}{*}{ ISD3 } & $-0.217 * * *$ & QUARTER3 & -0.000429 \\
\hline & $(0.0163)$ & & $(0.00256)$ \\
\hline \multirow[t]{2}{*}{ ISD4 } & 0.0589 & LOG(P_LAG1) & $0.265 * * *$ \\
\hline & $(0.0431)$ & & $(0.00566)$ \\
\hline \multirow[t]{2}{*}{ ISD6 } & -0.0651 & LOG(P_LAG2) & $0.200 * * *$ \\
\hline & $(0.0632)$ & & $(0.00552)$ \\
\hline \multirow[t]{2}{*}{ ISD7 } & $-0.216 * * *$ & LOG(P_LAG3) & $0.132 * * *$ \\
\hline & $(0.0481)$ & & $(0.00527)$ \\
\hline ISD8 & $-0.276 * * *$ & SALES & $0.00587 * * *$ \\
\hline
\end{tabular}




\begin{tabular}{ll|ll}
\hline & $(0.0300)$ & & $(0.000168)$ \\
\hline ISD9 & $-0.142^{*}$ & MAP & $-0.0910^{* * *}$ \\
\hline ISD12 & $(0.0837)$ & & $(0.00502)$ \\
\hline & $-0.279 * * *$ & POSTMAP & $0.00962^{* *}$ \\
\hline Constant & $(0.0139)$ & & $(0.00436)$ \\
\hline & $3.583^{* * *}$ & Observations & 95148 \\
\hline
\end{tabular}

Robust standard errors in parentheses.

* significant at 10 percent; $* *$ significant at 5 percent $* * *$ significant at 1 percent. 
Table 4. MAP Impact on Sales Prices for Alternative Specifications.

Dependent Variable: Log (Sales Price)

\begin{tabular}{|c|c|c|c|c|}
\hline Variable & OLS & SEM-4 & OLS & SEM-4 \\
\hline \multirow[t]{2}{*}{$M A P$} & $-0.0910 * * *$ & $-0.1227 * * *$ & & \\
\hline & $(0.00502)$ & $(0.00476)$ & & \\
\hline \multirow[t]{2}{*}{ POSTMAP } & $0.00962 * *$ & $0.0133 * * *$ & & \\
\hline & $(0.00436)$ & $(0.00363)$ & & \\
\hline \multirow[t]{2}{*}{$M A P \_1$} & & & $-0.0919 * * *$ & $-0.1212 * * *$ \\
\hline & & & $(0.00512)$ & $(0.0048)$ \\
\hline \multirow[t]{2}{*}{ MAP_2 } & & & $-0.0865 * * *$ & $-0.1163 * * *$ \\
\hline & & & $(0.0101)$ & $(0.0093)$ \\
\hline \multirow{2}{*}{ MAP_3_4 } & & & $-0.0781 * * *$ & $-0.1094 * * *$ \\
\hline & & & $(0.00935)$ & $(0.0088)$ \\
\hline \multirow[t]{2}{*}{ MAP_5_10 } & & & $-0.0873 * * *$ & $-0.1205^{* * *}$ \\
\hline & & & $(0.00908)$ & $(0.0089)$ \\
\hline \multirow{2}{*}{ MAP_10 } & & & $-0.101 * * *$ & $-0.1250 * * *$ \\
\hline & & & $(0.0114)$ & $(0.0116)$ \\
\hline \multirow[t]{2}{*}{ POSTMAP_1 } & & & $0.0208 * * *$ & $0.0220 * * *$ \\
\hline & & & $(0.00510)$ & $(0.0042)$ \\
\hline \multirow[t]{2}{*}{ POSTMAP_2 } & & & 0.0156 & $0.0160 *$ \\
\hline & & & $(0.00964)$ & $(0.0085)$ \\
\hline \multirow[t]{2}{*}{ POSTMAP_3_4 } & & & -0.00463 & 0.0012 \\
\hline & & & $(0.00904)$ & $(0.0083)$ \\
\hline \multirow[t]{2}{*}{ POSTMAP_5_9 } & & & -0.00322 & -0.0015 \\
\hline & & & $(0.00889)$ & $(0.0086)$ \\
\hline \multirow[t]{2}{*}{ POSTMAP_10 } & & & -0.0189 & $-0.0249 * *$ \\
\hline & & & $(0.0115)$ & $(0.0116)$ \\
\hline \multirow[t]{2}{*}{$L A M B D A$} & & $0.4120 * * *$ & & $0.4069 * * *$ \\
\hline & & $(0.000)$ & & $(0.001)$ \\
\hline \multirow[t]{2}{*}{ Constant } & $3.679 * * *$ & $4.3496 * * *$ & $3.698 * * *$ & $4.3573 * * *$ \\
\hline & $(0.0472)$ & $(0.000)$ & $(0.0474)$ & $(0.000)$ \\
\hline Observations & 95148 & 95148 & 95148 & 95148 \\
\hline R-squared & 0.896 & 0.91 & 0.897 & 0.912 \\
\hline
\end{tabular}


${ }^{1}$ The FHA 203B limit is adjusted annually, and it is $\$ 200,160$ for Dallas County in 2006.

${ }^{2}$ Approximately 4 percent of the participants received funding from resources other than MAP, such as the county down payment assistance program, city bond program, Federal Home Loan Bank, Helping Hands, and lenders' programs. . This study does not differentiate the impact of MAP from that of other sources because the fund has been used for similar purposes.

${ }^{3}$ The MAP manual is available at http://www.dallasmap.org under "Exhibits and Forms."

${ }^{4}$ Housing Quality Standards was renamed Minimum Housing Standards (MHS) in 2007.

${ }^{5}$ Results with various ring sizes are similar to those with 1,000 feet and available upon request from the authors.

${ }^{6}$ Note that by including the lagged values, we lose 3 years of observations and end up with 95,148 total observations, as stated above.

${ }^{7}$ More detailed summary statistics are available from authors upon request.

${ }^{8}$ Estimating equation (1) with block group fixed effects did not alter the direction of the impacts of MAP, and the precision is slightly decreased although the estimates are still statistically significant.

${ }^{9}$ The matrix is sparse in the sense that most of the entries are zero. Each row has only four nonzero elements associated with that observation's neighbor. This sparsity makes it possible to use more efficient computer algorithms than those that rely on dense matrix routines.

${ }^{10}$ Regression reported in Table 4 and Table 3 includes the same set of variables in X, Z and T.

${ }^{11}$ See Hollister (2008), Nathan (2008) and the related discussion in volumes 27(3) and 28(1) of the Journal of Policy Analysis and Management. 